\title{
Aplicação do método Delphi na prática de serviços ambientais em mananciais
}

\author{
Application of the Delphi method in the practice of \\ environmental services in watersheds
}

Data de entrada: 01/06/2016

Data de aprovação: 28/04/2017

\section{Resumo}

Os projetos de serviços ambientais de proteção aos recursos hídricos são crescentes e atrelados aos programas de pagamento por serviços ambientais. Os serviços ambientais praticados nas bacias hidrográficas são cada vez mais pesquisados, sendo que a regulação da vazão e a melhoria da qualidade da água são parâmetros essenciais. A escassez hídrica e o aumento acelerado da população tornam os mananciais cada vez mais estratégicos, sendo ponto chave para governança e ações de tomada de decisão. O presente artigo tem por objetivo apresentar a aplicabilidade do método Delphi para ajudar o Governo do Estado de São Paulo, Brasil, no programa de pagamento por serviços ambientais para a proteção das nascentes. A metodologia utilizada, o método Delphi, consistiu em revisão da literatura e estudo de caso do projeto Mina d'água, da Secretaria de Estado do Meio Ambiente do Governo de São Paulo em parceria com os municípios e produtores rurais. Os resultados da aplicabilidade do método Delphi representam uma ferramenta útil de comunicação entre os grupos de especialistas e do público, tornando possível a formação de um julgamento melhor e consistente para o processo de tomada de decisão. Palavras-chave: Serviços ambientais. Método Delphi. Bacias hidrográficas.

\section{Abstract}

Environmental services projects to protect water resources are increasing and linked to payment programs for environmental services. The environmental services practiced in the river basins are increasingly researched, and the regulation of the flow and the improvement of water quality are essential parameters. Water scarcity and rapid population growth make water resources increasingly strategic as a key to governance and decision-making. The purpose of this article is to present the applicability of the Delphi method to help the Government of the State of São Paulo, Brazil, in the payment for environmental services program for the protection of springs. The applied methodology, the Delphi method, consisted on a review of the literature and a case study of the Mina d'água project of the State Department of Environment of the Government of São Paulo in partnership with municipalities and rural producers. The results of the applicability of the Delphi method represents a useful tool for communication among the groups of experts and the society, making possible the formation of a better judgment and consistent for the decision-making process.

Keywords: Environmental services. Delphi Metods. Watersheds.

\footnotetext{
Carlos Alberto Mariottoni - Professor titular da Faculdade de Engenharia Civil, Arquitetura e Urbanismo da Unicamp e no Programa de PósGraduação da FEC, em Recursos Hídricos, Energéticos e Ambientais. Coordenador do GPESE-Grupo de Planejamento Energético e Sistemas Elétricos da FEC/NIPE-UNICAMP.

Claudete Bezerra dos Santos Canada - Doutora em Engenharia Civil pela Unicamp, na área de Recursos Hídricos, Energéticos e Ambientais. Membro do GPESE - Grupo de Planejamento Energético e Sistemas Elétricos da FEC/NIPE-UNICAMP e da Redipasa - Rede Iberoamericana de Pagamento por Serviços Ambientais.

"Endereço para correspondência: Rua Padre Eustáquio, 490 - Vila Idalina - Poá - SP, CEP.08562-400.
} 


\section{INTRODUÇÃO}

Métodos multicritérios têm sido muito utilizados na solução de problemas de tomada de decisão, uma vez que procuram esclarecer ao decisor as possibilidades de escolhas, apoiando assim o processo decisório embasado nas informações existentes. A tomada de decisão por um gestor, independentemente de sua área de atuação, leva em consideração alguns critérios, definidos previamente, objetivando a melhor decisão a ser tomada. Segundo Oliveira (2003), decidir é escolher entre alternativas, tomar decisão é o mesmo que emitir uma opinião, sentenciar, resolver, optar.

Os métodos multicritérios sugerem uma interação com os decisores envolvidos com a questão para a definição dos critérios e parâmetros de seleção, conduzindo a resultados mais consistentes (ENSSLIN, L; MONTIBELLER NETO, G. e NORONHA, S.M., 2001). A Análise Multicritério tem sido empregada para geração de indicadores de sustentabilidade de atividades agropecuárias (TÔSTO et al. 2013), geração de indicadores de sustentabilidade de cana de açúcar (TÔSTO e PEREIRA, 2011), valoração de ativos ambientais (OSPINA, 2012) e como ferramenta para gestão da biodiversidade (RIASCOS, 2010), identificação de elementos chave de sistema territorial, como uma perspectiva de sistemas complexos para geração de uma proposta de ordenamento territorial em distritos agrícolas (VAN DEN BOSCH, 2008), como suporte metodológico para gestão de conflitos do uso de recursos hídricos (FIGUEROA, 2007) e para gestão florestal (VARGAS, 2003).

$\mathrm{Na}$ aplicação desses métodos, a delimitação do problema poderá ter diferentes enfoques, como é o caso relacionado com as reais demandas da gestão de recursos hídricos no Brasil. Na questão do Brasil, que concentra uma das maiores reservas de água doce do mundo, aliada à sua biodiversidade e à beleza dos seus rios e lagos, representa um importante patrimônio natural do país; entretanto, os problemas relacionados à distribuição espacial e temporal da água têm representado enormes desafios para milhares de brasileiros. Os mananciais se tornam cada vez mais estratégicos para a sobrevivência das cidades devido ao aumento acelerado da demanda e do comprometimento qualitativo da água destinada ao abastecimento das populações urbanas. Em regiões como a Metropolitana de São Paulo (RMSP), a disponibilidade atual de água corre sérios riscos, devido à contínua expansão da ocupação urbana desordenada, visando os diferentes tipos de usos (industrial, agrícola, mineração, entre outros), provoca a poluição e contaminação dos mananciais.

A poluição dos corpos d'água pelas descargas diretas de esgoto, cargas não-pontuais e as inundações frequentes associadas à alta impermeabilização do solo também caracterizam a situação de conflito quanto ao uso dos recursos hídricos e de deficiência do saneamento na região, prejudicando a qualidade de vida da sua população, principalmente daqueles que moram nos bairros mais pobres da cidade e que sofrem de perto os efeitos perversos da poluição e das enchentes (PORTO, 2003). Segundo Crizón et al (2002), essa metodologia é uma ferramenta na identificação de estratégia e conservação e conceitua que "a identificação de oportunidades de conservação e implementação de ferramentas de manejo da paisagem e onde existam múltiplos objetivos e grande diversidade de visões, podem ser problemáticas se não seguir um processo lógico e bem estruturado de análise.

Chegar a um acordo sobre a importância relativa de um critério ou indicador pode ser um trabalho difícil e complexo, mas necessário e relevante em uma tomada de decisão". No caso de políticas ambientais, esse tipo de ferramenta proporciona um marco diferente, que contribui com o processo de tomada de decisão (MARTINEZ et al. 2004). Segundo Gomes et al (2009), a tomada de decisão é um processo complexo, pois quase sempre precisa atender a múltiplos objetivos, que nem sempre poderão ser medidos quantitativamente, mas qualitativamen- 
te. As decisões, entretanto, são tomadas sem a devida apreciação do cenário e suas influências, em grande parte devido à complexidade dessa análise, baseando a escolha em julgamentos meramente intuitivos ou meramente quantitativos.

A análise multicritério não visa solucionar o problema, elegendo uma única verdade, mas almeja, como seu nome indica, apoiar o processo decisório, fazendo recomendações de ações específicas para cada decisor.

$\mathrm{Na}$ gestão de recursos hídricos, o instrumento de Pagamento por Serviços Ambientais (PSA) surge no Brasil e visa incentivar, por meio de pagamentos aos proprietários rurais, ações importantes para a geração de serviços ambientais (sequestro de carbono, conservação da biodiversidade, proteção de bacias hidrográficas: preservação da quantidade e qualidade de água).

O pagamento por serviços ambientais consiste em pagamentos diretos por aqueles que se beneficiam desses serviços (PORRAS, 2012). Esses pagamentos podem ser contratuais e condicionais, aos proprietários de terras e aos usuários locais, em retorno da adoção de práticas que garantam a conservação ou a restauração do ecossistema, representando uma forma nova e mais direta para promover a conservação (WUNDER, 2005).

Para Pattanayak (2004), os serviços ambientais oferecidos por bacias hidrográficas podem ser mensurados por alterações positivas nas medidas de escoamento de superficial, vazão de cursos de água, erosão de solo e produção de sedimentos. Pagiola (2005) relata que PSA consiste na venda de serviços prestados pelas florestas (individualmente ou em conjunto). Nesse contexto, dentro de uma bacia hidrográfica o PSA baseia-se em ressarcir um provedor pelo serviço ambiental que este fornece (princípio do provedor-recebedor).

Estudos científicos relatam que as florestas geram serviços ambientais; é como se fosse um "trabalho voluntário" que as mesmas realizam e que favorecem o ser humano e o planeta como um todo (Forest Trend, 2009). O tema das florestas vem sendo amplamente discutido e tem um papel indutor de gerar serviços ambientais, dentre eles: conservação da biodiversidade, sequestro e estoque de carbono, ciclagem de nutrientes, manutenção das chuvas, estabilidade do clima, manutenção da beleza estética, preservação cultural. Na relação floresta-água pode-se considerar que as florestas protegem os solos contra erosão, favorecem a infiltração, reduzem o escorrimento superficial e garantem a recarga dos mananciais e aquíferos, assim como ajudam a regular a vazão entre as épocas das cheias e da seca (GUEDES etal, 2011).

Para conservação da biodiversidade e para regulação climática do planeta, as florestas são fundamentais. Na maior parte dos casos, florestas podem adicionar mais valor se incorporadas dentro de estratégias mais amplas de manejo de bacias, incluindo outros usos de solo, e outras medidas conservacionistas (LANDELL-MILLS; PORRAS, 2002; ROUMASSET, 2013). Os impactos das florestas dependem muito de características próprias do local, do uso alternativo do solo e do manejo adotado.

De acordo com Tucci e Mendes (2006), a vegetação tem um papel fundamental no balanço de energia e no fluxo de volumes de água.

Nesse contexto, no âmbito de um projeto de PSA-Água, pode-se transacionar sobre as práticas de conservação de remanescentes florestais, de restauração ecológica e florestal, de regeneração assistida e de conservação do solo para a amenização de processos erosivos em áreas prioritárias para a produção de água (VEIGA, 2010). Tais incentivos ambientais, portanto, demonstram dinamismo e contundente potencial como instrumentos econômicos de gestão voltados ao manejo integrado de microbacias hidrográficas (FARLEY et al, 2010). 
A escassez de certos recursos ambientais e a busca constante de saídas para controlar e explorar de forma sustentável esses bens e serviços naturais levou o Governo do Estado de São Paulo a criar um instrumento legal para dar subsídios ao Projeto Mina d'água, que institui o Pagamento por Serviços Ambientais para a proteção de nascentes localizadas em áreas de mananciais de abastecimento público (São Paulo, 2009). Dentro do aspecto legal no Brasil, ainda é incipiente e não construída de forma declaratória em uma legislação de âmbito nacional que corresponda os anseios dos esquemas de PSA. O presente artigo tem como objetivo utilizar o método Delphi no auxílio de tomada de decisão ao Governo do Estado de São Paulo, Brasil, visando garantir o pagamento às práticas de serviços ambientais em áreas de mananciais de abastecimento público.

\section{MATERIAIS E MÉTODOS}

Este trabalho realizou levantamento bibliográfico e pesquisa documental, levantamento de dados do Projeto Mina d'Água e sua modalidade de proteção de nascentes, avaliou a cooperação ocorrida entre a Secretaria do Meio Ambiente do Estado de São Paulo e os municípios abrangidos por meio de convênios, bem como o pagamento de serviços ambientais para proteção de nascentes localizadas em áreas de mananciais. Para utilização da análise de multicritério foi utilizado o método Delphi (SANTOS etal, 2005; WRIGHT, et al, 2000).

O Projeto Mina d'Água iniciou a fase piloto do projeto firmando um acordo com 21 municípios em Unidade de Gerenciamento de Recursos Hídricos (UGRH), com proteção de 150 nascentes. Para aplicabilidade da análise de multicritérios foi utilizado o Método Delphi, sendo o mesmo aplicado em 5 pesquisadores focados nos projetos de pagamento por serviços ambientais da Secretaria do Meio Ambiente do Estado de São Paulo. Esses profissionais possuem grande experiência e práti- ca no Pagamento por Serviços Ambientais - PSA, sendo responsáveis pela implantação e fiscalização em projetos no âmbito estadual; portanto, as contribuições realizadas por meio das respostas aos questionários são plenamente condizentes com a realidade e as práticas atuais. Para a elaboração do cenário foi utilizada a técnica Delphi, na qual especialistas respondem exaustivamente rodadas de questionários, em busca de consenso de suas opiniões sobre eventos futuros (SANTOS, et al, 2005). No caso desta pesquisa Delphi, o consenso foi alcançado na segunda rodada de questionários. A técnica Delphi, conforme Linstone e Turoff (1975, p. 3), é um "método de estruturação de um processo de comunicação grupal, que é efetivo para permitir a um grupo de indivíduos, como um todo, tratar um problema complexo".

Para aplicabilidade do método Delphi decidiu-se utilizar um processo de consulta em duas fases de um grupo interdisciplinar de 5 especialistas da Secretaria de Estado do Meio Ambiente. O fato de considerar o consenso deixa de fora opiniões que, embora divergentes, reúnam garantia para aplicabilidade do PSA.

A pesquisa foi iniciada em março e finalizada em setembro de 2011, tendo sido realizada com base nas seguintes etapas:

1) análise preliminar dos objetivos: definir os elementos primários de avaliação envolvidos no problema da pesquisa e elaborar uma lista de possíveis especialistas da Secretaria de Estado do Meio Ambiente; 2) elaboração das perguntas: com base nos resultados, a coordenação elaborou um documento de base e um questionário com perguntas abertas, sobre os seguintes temas: arranjo institucional na garantia da implementação e gestão do projeto; a área abrangida (propriedade rural), os serviços ambientais, os recursos financeiros e o monitoramento dos resultados atingidos; 3 ) Mapa Cognitivo: respostas dos especialistas que responderam por escrito e, em alguns casos, foi 
feita uma complementação por meio de entrevistas diretas; 4) Objetivos, fins e meios: elaboração das respostas e segunda consulta aos especialistas: as respostas foram elaboradas, reordenadas por temas e submetidas, novamente, aos mesmos especialistas, em um segundo questionário com critérios pré-estabelecidos. Com isso, obteve-se o consenso ou o dissenso sobre cada uma das hipóteses surgidas durante a primeira consulta. É importante destacar que os especialistas não sabiam quem fazia parte do painel durante toda a realização da pesquisa; 5) elaboração dos resul- tados: a pesquisa foi concluída com a elaboração das respostas, a seleção dos critérios aceitáveis (aquelas que receberam 5 indicações consensuadas entre todos especialistas), a análise dos resultados, a definição do critério.

Para este estudo de caso, os objetivos iniciais estão relacionados ao arranjo institucional na garantia da implementação e gestão do projeto; à área abrangida, aos serviços ambientais, aos recursos financeiros e ao monitoramento dos resultados atingidos. A Figura 1 demonstra as etapas usuais de uma pesquisa com o Método Delphi.

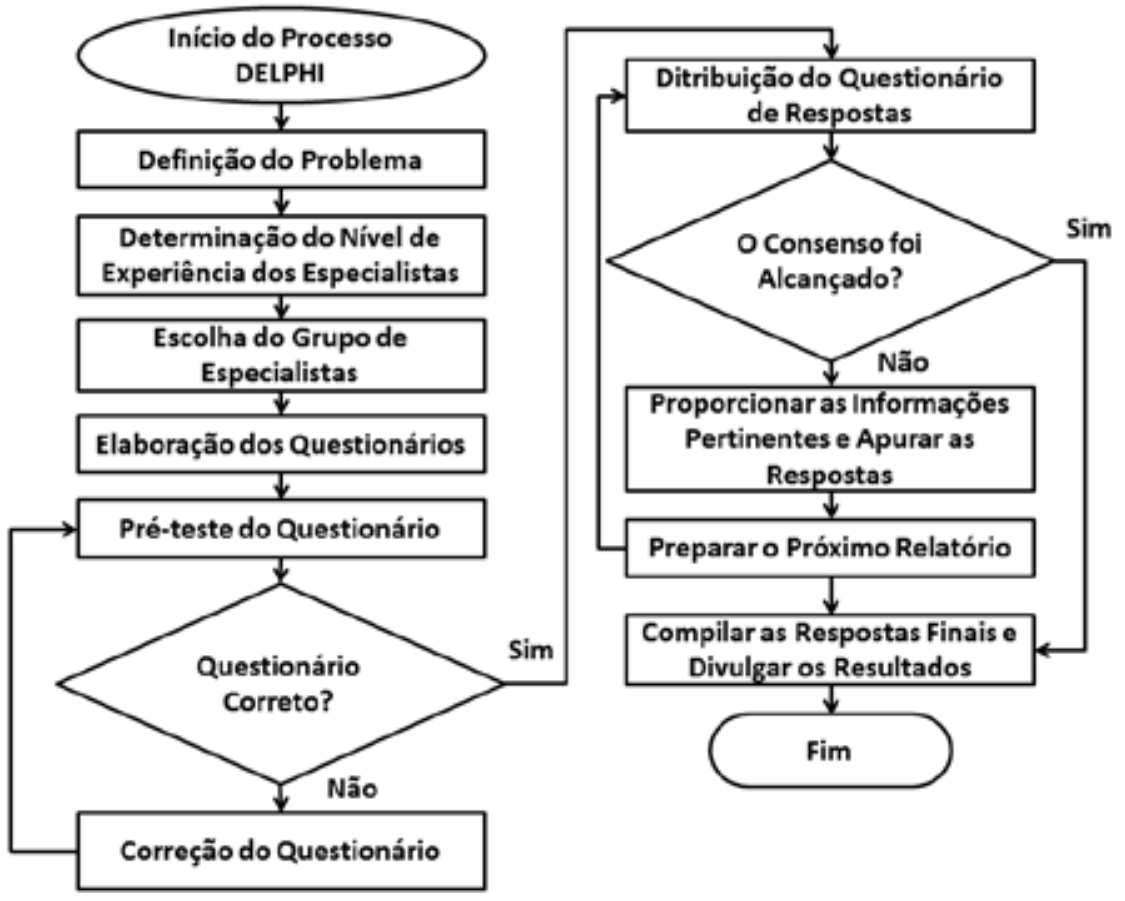

Figura 1 - Etapas usuais de uma pesquisa com o Método Delphi (Adaptado de Godet (1993) e Landeta, 1999)

\subsection{Estudo de caso: Projeto Mina d'Água}

O Projeto Mina D’água foi executado sob a responsabilidade da Coordenadoria de Biodiversidade e Recursos Naturais - CBRN com o apoio da Coordenadoria de Recursos Hídricos - CRHi, do Gabinete da Secretaria do Meio Ambiente e de forma integrada com os Projetos Ambientais Estratégicos Município VerdeAzul e Mata Ciliar, o Projeto Adote Uma Nascente e o Pacto das Águas (Resolução SMA No 123).

O Projeto Mina D’água contempla exclusivamente ações voltadas à proteção de nascentes situadas 
em mananciais de abastecimento público, incluindo: eliminação de fatores de degradação, tais como presença de animais, fogo, focos de erosão, entre outros; execução de ações que favoreçam a regeneração natural da vegetação, tais como eliminação de espécies competidoras, implantação de técnicas de nucleação, entre outras; o plantio de mudas de espécies nativas de ocorrência regional; monitoramento e vigilância.

As áreas prioritárias são previamente definidas pelo município, à montante da captação ou tomada d'água, até 150 nascentes por município e no máximo 4 nascentes por produtor. A participação no Projeto estará condicionada à comprovação da inexistência de qualquer pendência do participante no Cadastro Informativo dos Créditos Não Quitados de Órgãos e Entidades Estaduais - Cadin Estadual.

Os provedores de serviços ambientais para o Projeto Mina d'água são selecionados pelas Prefeituras Municipais dentre os produtores rurais das áreas prioritárias, dando-se preferência a agricultores familiares, conforme definido na Lei Federal 11.326 de 24 de julho de 2006, e assegurando-se a observância dos princípios de publicidade, isonomia e impessoalidade. Cabe aos municípios conveniados solicitar recursos financeiros, sob a forma de crédito não reembolsável, do Fundo Estadual de Prevenção e Controle da Poluição - Fecop para a execução de projetos de pagamento por serviços ambientais.

A participação como provedor de serviços ambientais no Projeto Mina d'água está condicionada à comprovação do uso ou ocupação regular do imóvel a ser contemplado e à adequação do mesmo em relação à legislação ambiental ou, se for o caso, a assinatura, junto à Secretaria do Meio Ambiente, de Termo de Compromisso de Adequação Ambiental no qual deverão ser estabelecidos as obrigações e os prazos para o cumprimento do que estabelece a legislação ambiental (Resolução SMA No 123).

Cabe ao município aprovar a lei municipal referente ao pagamento por serviços ambientais e a existência em seus quadros funcionais de profissionais para a realização de atividades de fiscalização.

A adesão aos Projetos de Pagamento por Serviços Ambientais é voluntária e deve ser formalizada por meio de contrato entre o produtor e a Prefeitura Municipal, no qual serão expressamente definidos os compromissos assumidos e demais condições a serem cumpridas pelo produtor para fazer jus à remuneração.

Quanto mais protegida estiver a nascente, e mais pessoas ela atender, maior será o valor pago pelo serviço ambiental prestado. O pagamento prevê a qualidade do serviço prestado, e não os custos com a recuperação. $O$ valor do pagamento a ser realizado ao produtor obedece a seguinte fórmula:

\section{Valor do pagamento $=V$ Ref $x(F$ Prot $+F$ Imp $) \times 0,2$}

>VRef: valor de referência definido com base no custo de oportunidade, varia regionalmente.

> FProt: fator de proteção da nascente relacionado ao esforço do proprietário para a geração do serviço ambiental que varia de 1 a 4 e representa $40 \%$ do peso. É considerada a presença de animais, fogo ou focos de erosão. Adota-se 1 para a nascente protegida e vegetação em estado inicial de regeneração; 2 para a nascente protegida e vegetação em estado médio de regeneração ou plantio de mudas e 4 para nascente protegida e vegetação em estágio avançado.

> FImp: considera a população atendida pela captação, a vazão de permanência em um ano hidrológico e a localização da nascente.

A Figura 2 demonstra o mapa do Estado de São Paulo e os municípios do Projeto Mina D’Água. 


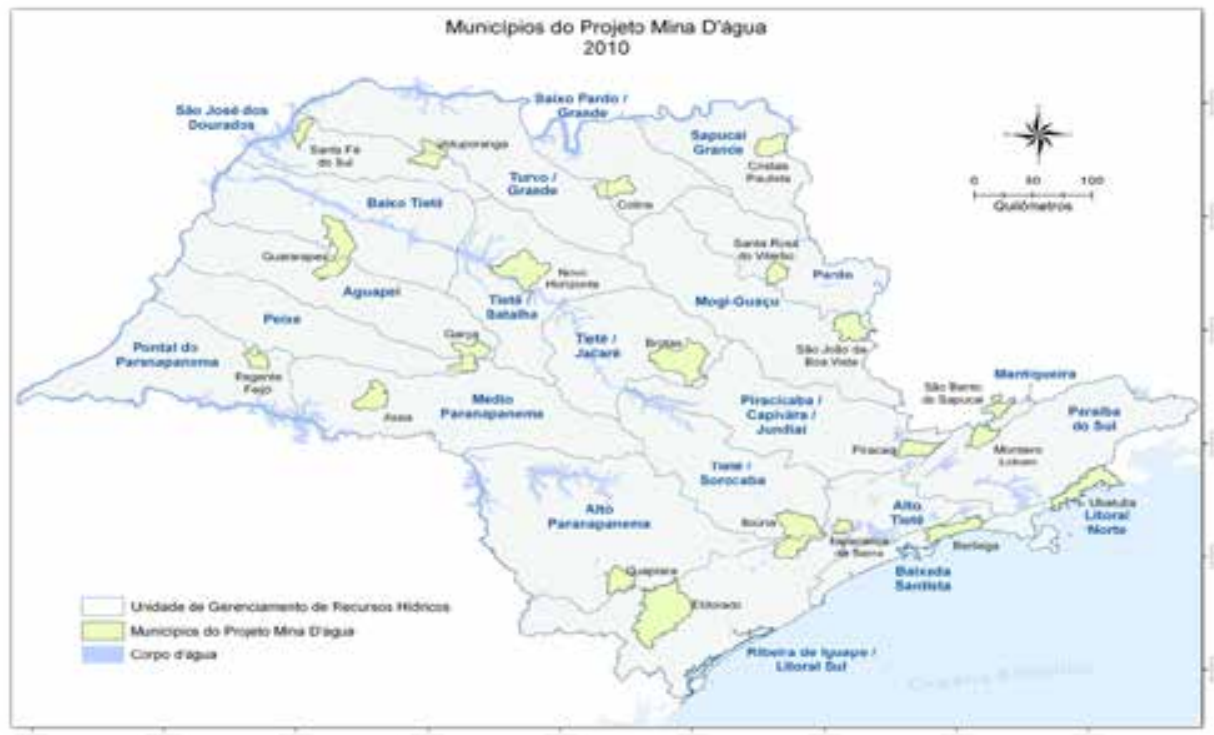

Figura 2 - municípios do Projeto Mina D’Água

\section{RESULTADOS}

Para entendimento da aplicabilidade do método Delphi e como este pode auxiliar na tomada de decisão no Projeto Mina d’Água, as etapas foram concluídas em duas rodadas com os 5 especialistas. A escolha dos 5 especialistas foi realizada com conhecimento na prática do pagamento por serviços ambientais e do Projeto Mina d’Água. Foi traçada a definição do problema "garantia do pagamento às práticas de serviços ambientais" aos especialistas de forma clara e abrangente.

Para análise inicial foram definidos os elementos primários para o início da $1^{\mathrm{a}}$ rodada. Na Figura 3, a seguir, podem ser visualizados os Elementos Primários de Avaliação - EPA's:

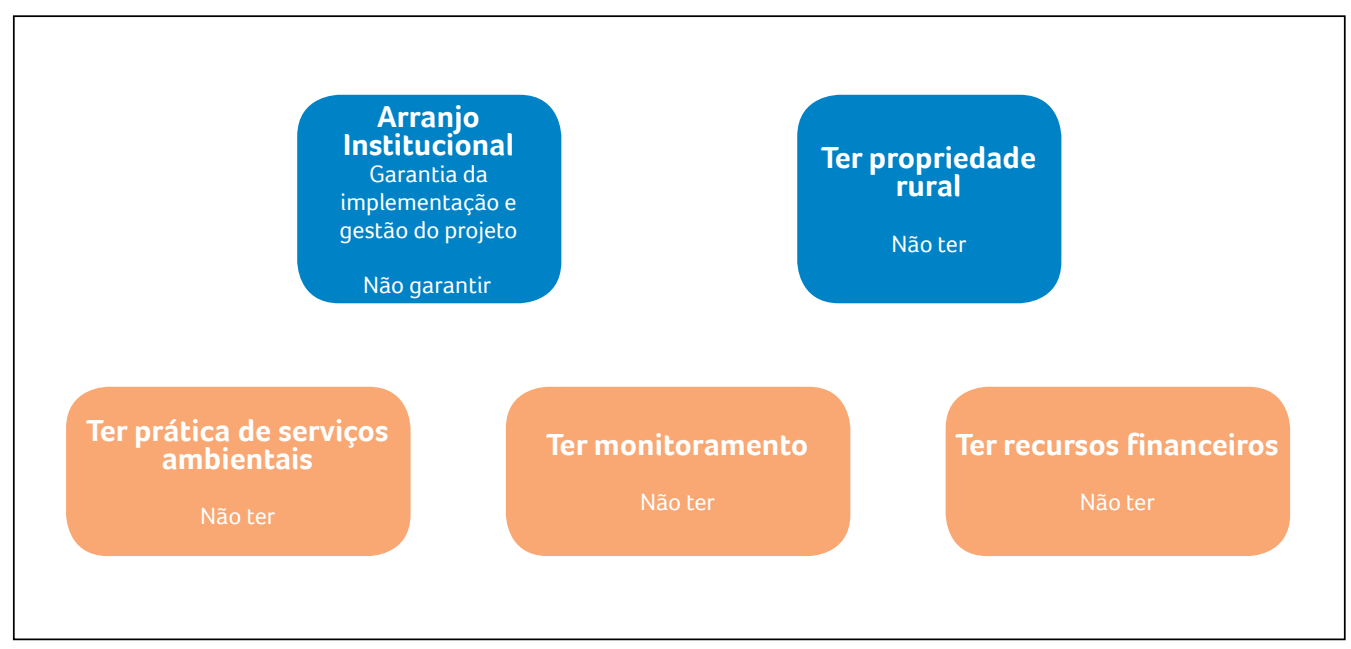

Figura 3 - Elementos Primários de Avaliação - EPA’s 
Desenvolvimento da primeira rodada: cada especialista do grupo recebeu uma folha para responder, sem ter o conhecimento dos participantes e também sem troca de ideias um com o outro, a seguinte pergunta: “Dentro dos elementos primários, quais são as garantias para a realização do pagamento por serviços ambientais?”.
As respostas da primeira rodada foram tabuladas e analisadas pela coordenação. Com os dados tabulados, foi desenvolvido o mapa cognitivo, visando promover o pagamento por serviços ambientais em áreas de mananciais conforme a figura 4 a seguir:

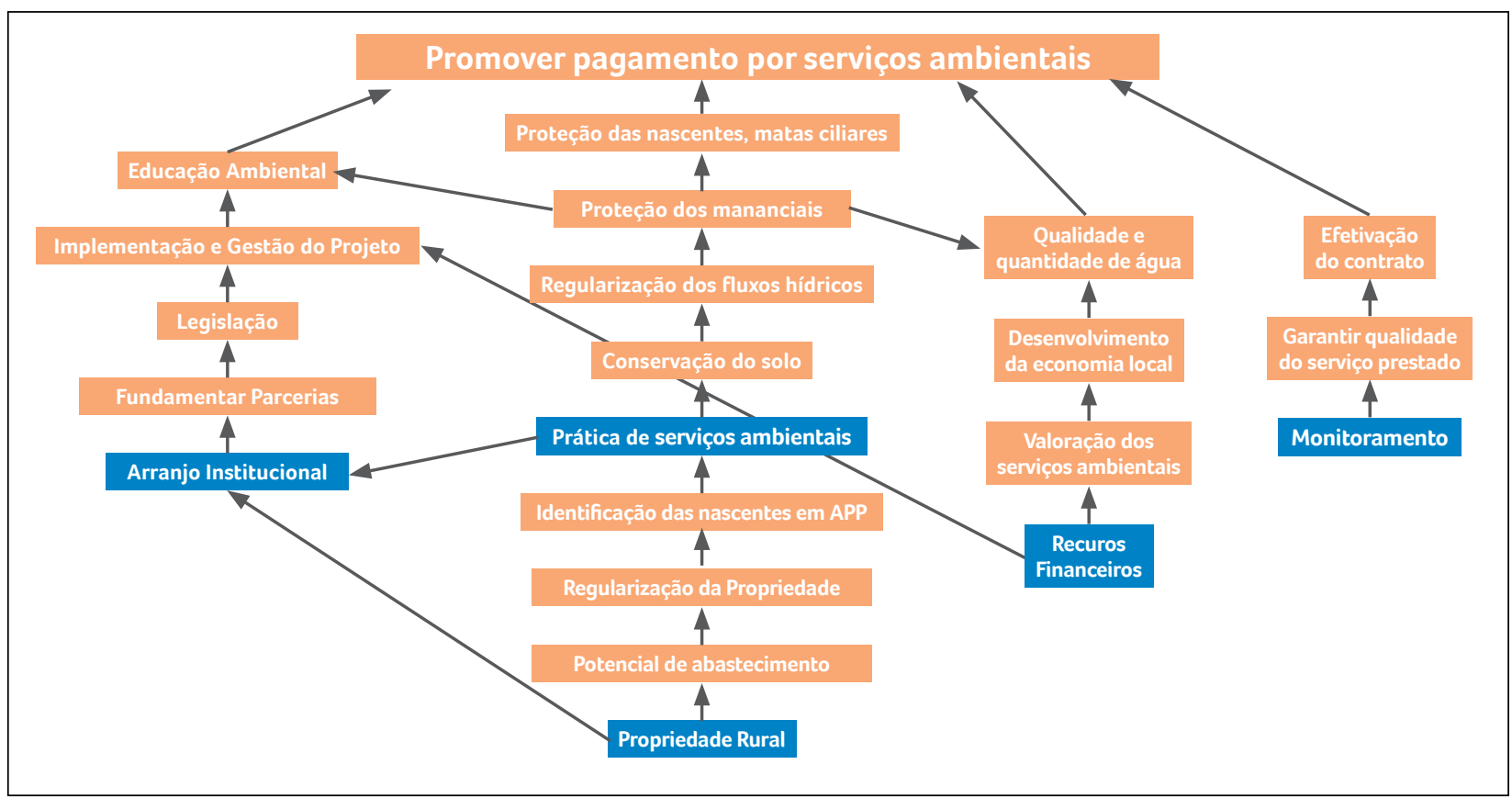

Figura 4 - mapa cognitivo

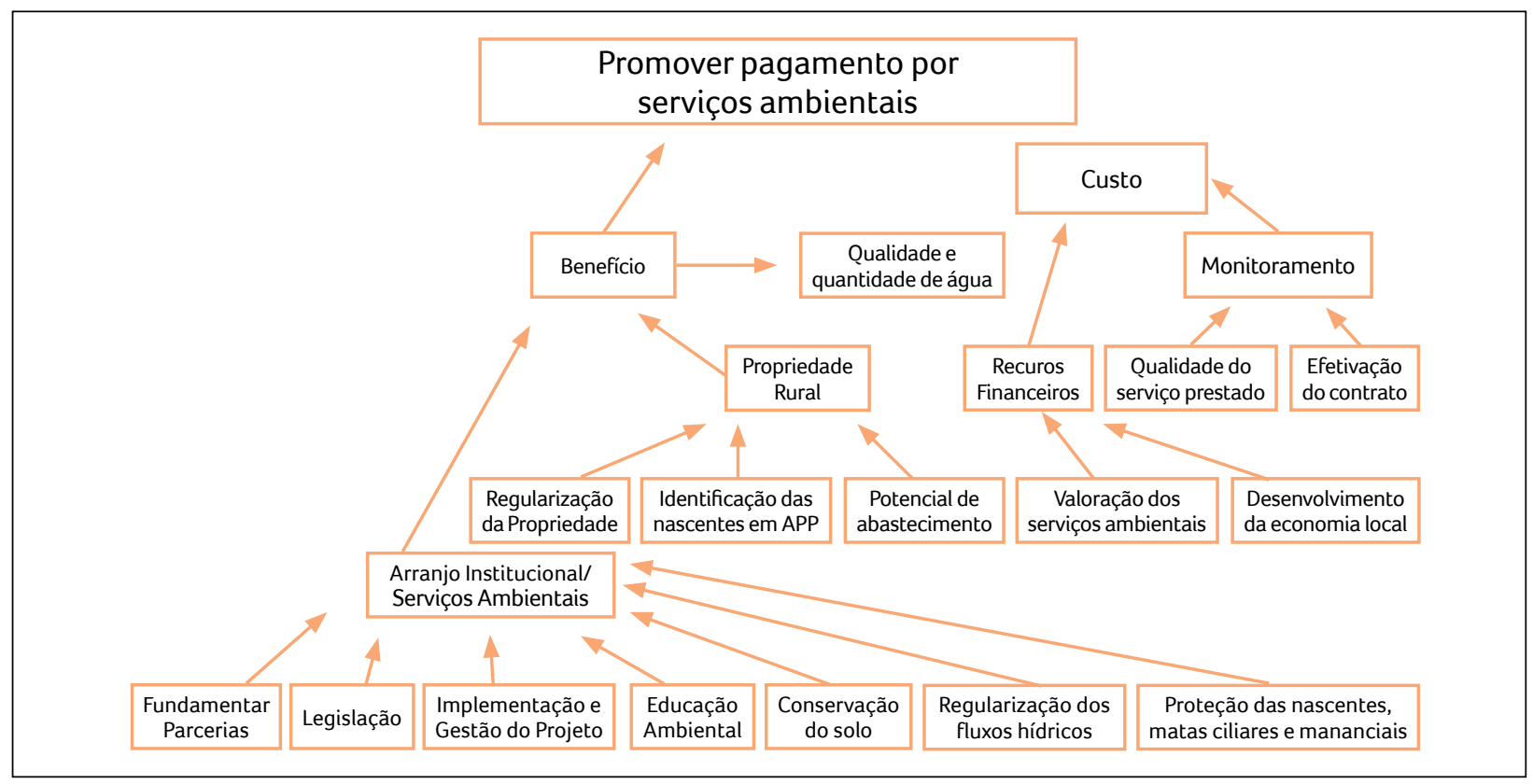

Figura 5 - objetivos, fins e meios 
Desenvolvimento da Segunda Rodada: os especialistas receberam um papel em que constava o mapa cognitivo definido na primeira rodada, bem como os objetivos, fins e meios definidos na primeira rodada (Figura 5). A pergunta feita a eles foi: "Você concorda com os critérios estabelecidos que correspondam exatamente à garantia ao pagamento por serviços ambientais? Pontue de 0 a 10". Respondida a pergunta e recolhidas às respostas de todos os especialistas, foi determinado o nível de concordância e consenso.
$\mathrm{Na}$ avaliação dos resultados, o critério qualidade do serviço prestado foi identificado pelos especialistas como o primeiro critério para garantia do pagamento às práticas de serviços ambientais em áreas de mananciais. A identificação dos critérios foi elaborada a partir do mapa cognitivo, objetivo, fins e meios. Os especialistas identificaram vários critérios e de maneira consensual observaram que a qualidade do serviço prestado e seguido da fundamentação de parcerias garante o PSA.

A tabela 1 a seguir demonstra os resultados alcançados após a aplicação do método Delphi.

Tabela 1 - Avaliação dos resultados

\begin{tabular}{|c|c|c|c|c|c|c|c|c|c|c|}
\hline Critérios & \#1 & \#2 & \#3 & \#4 & \#5 & Q1 & Q2 & Q3 & Média & $\%$ Pesos \\
\hline Arranjo Institucional & 0 & 10 & 8 & 9 & 10 & 8,00 & 9,00 & 10,00 & 7,40 & $5,6 \%$ \\
\hline Serviços Ambientais & 8 & 9 & 10 & 10 & 0 & 8,00 & 9,00 & 10,00 & 7,40 & $5,6 \%$ \\
\hline Fundamentar Parcerias & 9 & 10 & 8 & 8 & 9 & 8,00 & 9,00 & 9,00 & 8,80 & $6,7 \%$ \\
\hline Legislação & 8 & 7 & 7 & 0 & 8 & 7,00 & 7,00 & 8,00 & 6,00 & $4,5 \%$ \\
\hline Implementação e Gestão do Projeto & 10 & 10 & 9 & 9 & 0 & 9,00 & 9,00 & 10,00 & 7,60 & $5,8 \%$ \\
\hline Educação Ambiental & 9 & 8 & 9 & 8 & 0 & 8,00 & 8,00 & 9,00 & 6,80 & $5,2 \%$ \\
\hline Conservação do solo & 10 & 9 & 10 & 9 & 0 & 9,00 & 9,00 & 10,00 & 7,60 & $5,8 \%$ \\
\hline Regularização dos fluxos hídricos & 9 & 9 & 10 & 9 & 0 & 9,00 & 9,00 & 9,00 & 7,40 & $5,6 \%$ \\
\hline Proteção das nascentes, matas ciliares e mananciais & 10 & 9 & 10 & 9 & 0 & 9,00 & 9,00 & 10,00 & 7,60 & $5,8 \%$ \\
\hline Regularização da Propriedade & 0 & 7 & 8 & 7 & 0 & 7,00 & 7,00 & 7,00 & 4,40 & $3,3 \%$ \\
\hline Propriedade Rural & 0 & 9 & 8 & 8 & 0 & 8,00 & 8,00 & 8,00 & 5,00 & $3,8 \%$ \\
\hline Qualidade e quantidade de água & 0 & 9 & 9 & 9 & 0 & 9,00 & 9,00 & 9,00 & 5,40 & $4,1 \%$ \\
\hline Identificação das nascentes em APP & 8 & 9 & 9 & 8 & 8 & 8,00 & 8,00 & 9,00 & 8,40 & $6,4 \%$ \\
\hline Potencial de abastecimento & 7 & 0 & 8 & 9 & 0 & 7,00 & 7,00 & 8,00 & 4,80 & $3,6 \%$ \\
\hline Recuros Financeiros & 8 & 0 & 8 & 9 & 9 & 8,00 & 8,00 & 9,00 & 6,80 & $5,2 \%$ \\
\hline Efetivação do contrato & 0 & 8 & 8 & 8 & 0 & 8,00 & 8,00 & 8,00 & 4,80 & $3,6 \%$ \\
\hline Valoração dos serviços ambientais & 8 & 0 & 7 & 0 & 9 & 7,00 & 8,00 & 8,00 & 4,80 & $3,6 \%$ \\
\hline Desenvolvimento da economia local & 7 & 6 & 0 & 8 & 0 & 6,00 & 7,00 & 7,00 & 4,20 & $3,2 \%$ \\
\hline Monitoramento & 10 & 9 & 10 & 9 & 0 & 9,00 & 9,00 & 10,00 & 7,60 & $5,8 \%$ \\
\hline Qualidade do serviço prestado & 10 & 10 & 10 & 8 & 8 & 8,00 & 10,00 & 10,00 & 9,20 & $7,0 \%$ \\
\hline
\end{tabular}

O critério "qualidade do serviço prestado" para garantia do pagamento por serviços ambientais no Projeto Mina d'Água resulta em indicadores de melhoria socioeconômica da região e os impactos previstos na redução da erosão do solo, redução de turbidez e assoreamento dos corpos d'água, regularização das vazões dos corpos d'água, aumento da cobertura vegetal, proteção e recuperação da biodiversidade regional, incrementos na produtividade agrícola e renda dos proprietários rurais auxiliam na gestão das bacias hidrográficas.

O PSA representa uma grande oportunidade de incentivo à manutenção da "floresta em pé", assim como para a promoção e execução de práticas sustentáveis para os produtores rurais. Considerando que os grandes fragmentos florestais e as áreas com maior cobertura florestal tendem 
a estar localizados em bacias hidrográficas com ocupação tipicamente rural, e que a agricultura é considerada uma atividade altamente consumidora de água, é necessária e relevante a remuneração aos produtores rurais para que, além da manutenção das florestas, promovam atividades de uso do solo que exerçam significativa influência sobre a capacidade de infiltração de água no solo (PAGIOLA et.al, 2013).

As boas práticas de conservação de remanescentes florestais, de restauração ecológica e florestal, de regeneração assistida e de conservação do solo para a amenização de processos erosivos em áreas prioritárias para a produção de água requerem tais investimentos. Alinhado à qualidade dos serviços prestados, o critério "fundamentar parceria" requer todos os atores envolvidos no esquema de PSA.

O site institucional da Secretaria de Estado do Meio Ambiente informa que o Projeto Mina d'água, em 2016, apresentava somente 5 Municípios participantes:

a) Guapiara (bacia do Alto Paranapanema) firmou 12 contratos com provedores de serviços ambientais; os contratos contemplam 197,28 ha de área e 31 nascentes, no valor de repasse de $\mathrm{R} \$ 38.850,00$ para 5 anos. Foram destacadas como áreas de abrangência do Projeto Mina d'Água as microbacias do Rio São José e do Ribeirão da Invernada.

b) Ibiúna (bacia do Sorocaba/Médio Tietê) firmou 8 contratos com provedores de serviços ambientais e repassou $\mathrm{R} \$ 2.610,00$ em PSA; área contratada de 376 ha, num total de 25 nascentes; foram selecionadas 03 regiões como áreas prioritárias: a microbacia do Ribeirão do Murundú, microbacia do Ribeirão do Paiol Grande e a sub-bacia do Alto Sorocabuçu.

c) Piracaia (bacia do Piracicaba/Capivari/Jundiaí) firmou 9 contratos com provedores de serviços ambientais, com 18 nascentes, somando 142,75 ha. Contratos para o repasse de R\$20.625,00 em 05 anos, e repassou $\mathrm{R} \$ 8.250,00$ em PSA do primeiro ano de proteção e recuperação das nascentes pelos provedores;

d) São Luís do Paraitinga (bacia do Paraíba do Sul) firmou 5 contratos com provedores de serviços ambientais no valor de $R \$ 10.500,00$ somando uma área de 200,8 ha e 12 nascentes, nas microbacias do Paraitinga e do Córrego da Queimada.

e) Votuporanga (bacia do Turvo/Grande) firmou 17 contratos com provedores de serviços ambientais e repassou $R \$ 37.800,00$ em PSA, com uma área de 922,55 ha e 32 nascentes, na microbacia do Córrego Marinheirinho.

\section{CONCLUSÕES}

A aplicabilidade do método Delphi constitui um fator relevante para a obtenção de dados mais consistentes e representa uma ferramenta útil de comunicação entre o grupo de especialistas ambientais, possibilitando a formação de um julgamento do grupo. A coleta de informações foi direcionada aos especialistas em duas rodadas; para análise das respostas foi observada a média dos critérios apontados na avaliação realizada pelos especialistas. Os resultados do método Delphi servem de base para a tomada de decisão e o auxílio no planejamento ambiental dos órgãos do Governo e empresas. No caso do Pagamento por Serviços Ambientais (PSA), os critérios identificados pelos especialistas auxiliam as linhas de ações para garantia do pagamento e serviços ambientais no Projeto Mina d'Água na proteção de nascentes ligadas ao abastecimento público. Existe uma grande necessidade de proteção das bacias hidrográficas que abrigam as fontes de captação de água para abastecimento. A degradação ambiental das bacias hidrográficas é decorrência da falta de comprometimento ambiental e da inade- 
quação das políticas públicas, da gestão e discussão com os atores envolvidos. $O$ papel das bacias hidrográficas tem sido um fator predominante nas tomadas de decisões para formulação de políticas públicas, auxiliando no planejamento e na gestão territorial.

\section{REFERÊNCIAS}

ARCADE, J.; GODET, M.; MEUNIER, F. e ROUBELAT, F. (1999). Structural Analysis With the MICMAC Method \& Actors' Strategy With MACTOR Method. Futures Research Methodology, American Council Is the United Nations University: the Millennium Project.

BRASIL.LEI No 11.326, DE 24 DE JULHO DE 2006. Estabelece as diretrizes para a formulação da Política Nacional da Agricultura Familiar e Empreendimentos Familiares Rurais. Disponível em: http://www.camara.gov.br/sileg/integras/837541.pdf. Acesso em 27 dezembro de 2016.

BRASIL. SÃO PAULO. Lei No 13.798, 09 de Novembro 2009. Estabelece a Política Estadual de Mudanças Climáticas.

BRASIL. SÃO PAULO. Secretaria de Estado do Meio Ambiente. Resolução Nº.123, de 24 Dezembro 2010.

CRIZÓN, I; GALVIS, N; MOURE, A. 2002. Guía Methodological Analisis Clinicos Multicriterio. Bogota: Alexander von Humboldt Institute.

ENSSLIN, L; MONTIBELLER NETO, G. e NORONHA, S. M. 2001. Support For Decision: Methodologies For Structuring Of Problems And Multi-Criteria Evaluation For Alternatives. Ed. Insular. Florianópolis, SC. (ISBN 85-7474-093-4)

FARLEY, J.;COSTANZA, R. Payments For Ecosystem Services: From Local To Global Ecological Economics, v.69, p. 2060-2068, 2010.

FIGUEROA, F.. Methodological support for the strategic management of conflicts related to the use of water resources. Tese (Doutorado em tecnologia ambiental e recursos hídricos) - Universidade de Brasília, 2007.

FOREST TREND. 2009. Learning about environmental services. The Katoomba Groups. Ecosystem Marketplace.

GODET, M. Manual for prospective Strategic. Lisboa: Publications Don Quixote, 1993.

GOMES, F. A. M.; GOMES, C. F. S.; ALMEIDA, A. T. of. 2009 managerial decision-making.: Focus Approvals. 3a ed. São Paulo: Editora Atlas.

GUEDES, F.B.; SEEHUSEN, N.R. Payments for environmental services in the Atlantic Forest: lessons learned and challenges. IBAMA, MMA, Brasília, 2011.
LANDELL MILLS, N; PORRAS, T. I. Silver Bullet Or Fools' Gold? The Global Review Of Markets For Forest Environmental Services And Their Impact On The Poor. Instruments For Sustainable Private Sector Forestry Series. The International Institute for Environment and Development, London, 2002.

LANDETA, J. . El Delphi method. Barcelona: Ariel, 1999.

LINSTONE H.A., TURROF, M. The Delphi Method, Techniques and Applications. Addison Wesley Publishing, 1999.

MARTíNEZ DE ANGUITA, P., RIVERA, S., BENEITEZ, J.M., Y CRUZ, F. Estabelecimiento de un mecanismo de pago por servicios ambientales sobre un soporte GIS en lacuenca del río Calan, Honduras. Geo-focus. Revista Internacional de Ciencia y Tecnología de la Información Geográfica 6:138-156, 2006.

OLIVEIRA, S.T. J e MORAES, L. F. R. de. Avaliação Multicritério de Projetos de Produção da Indústria de Petróleo no Brasil: Uma Análise Comparativa dos Métodos PROMETHEE E TODIM. Dissertação (Mestrado em Engenharia de Produção) - UFF, 2003.

OSPINA, M.J. Aplicación del Multicriterio Model. Metodologías AHP Y GP to la Valoración Economic de los Ambientales Assets. Dissertação (Mestrado em Administração) - Universidad Nacional de Colombia.

PAGIOLA, S.,BISHOP, J., e LANDER-mills. Markets For Ecosystem Services: Economic Instruments For Conservation And Development. REBRAF, RJ, 2005.

PAGIOLA, S.; GLEHN, H.C.VON; TAFFARELO, D. Experiências de Pagamentos por Serviços Ambientais no Brasil. $1^{\mathrm{a}}$ ed., São Paulo: SMA/CBRN, 2013.

PATTANAYAK, S. K. "Valuing Watershed Services: Concepts and Empirics From Southeast Asia". Agriculture, Ecosystem and Environment, 2004, 104(1): 171-184.

PORRAS, I. et al. De Rio a Riot: Lecciones de 20 Años de Experiência en Servicios Ambientales en Costa Rica. $1^{\text {a }}$ ed. London: International Institute for Environment and Development, 2012.

PORTO, M.A. Water Resources and Sanitation in the Metropolitan Region of São Paulo: a Challenge of the Size of the City.1st edition .Brasilia, 2003.

RIASCOS, E.M. El Analisis Clinicos Multicriterio en la Gestión de la Biodiversidad. Dissertação (Mestrado em Meio Ambiente e Desenvolvimento) - Universidad Nacional de Colombia, 2010.

ROUMASSET, J., WADA, C.A.. A Dynamic Approach to PES Pricing and Finance of Interlinked Ecosystem Services: Watershed Conservation and Groundwater Management. Ecological Economics 87, pg. 24-33, 2013.

SANTOS, A.; VIDOTTO, L.S.; GIUBLIN, C.R. A Utilização do Método Delphi em Pesquisas na Área da Gestão da Construção. Ambiente Construído, Porto Alegre, v. 5, n. 2, p. 51-59, abr./jun. 2005. 
TÔSTO, S.G e PEREIRA, L.Ch. 2011. Environmental Sustainability Index Based On Multi-Criteria Analysis Of Decision Support. In: 9Th meeting of the Brazilian Society of ecological economics - ECOECO. 2011, Brasília. 16 p.

TÔSTO, S.G.; PEREIRA, L.C; ROMEIRO, A.R. e Mangabeira, J.A.C.. Determination of environmental sustainability index: a multi-criteria analysis contribution for the formulation of public policies. In: $\mathbf{X}$ meeting of the Brazilian Society of ecological economics - ECOECO. 2013, Vitória.

TUCCI, C.E.M.; MENDES, A.C. . Integrated environmental evaluation of River Basin. Institute of Environment and Renewable Natural Resources. Brasília, MMA, 2006.

VAN DEN BOSCH, M.A. Un model de desarrollo sustentable en las areas bajo riego de los districts Ugarteche y el Carrizal winery. Department of Lujan de Cuyo. Província de Mendoza: un inflow to el ordenamiento territorial rural. Dissertação (Mestrado em Planejamento Estratégico) - Universidad Nacional de Cuyo, 2008.

VARGAS, O.L. 2003. La evaluación multicriterio social y su en la gestión forestal potential of Colombia. De Trabajo de investigación process ofb eing presented as partial requirement to apply for el title of Doctor en Ciencias Ambientales. Barcelona: Universidad Autónoma of Barcelona.

VEIGA, F. 2010. Methodologies for deployment in water resources. The Nature Conservancy.

WRIGHT, J. T. C.; GIOVINAZZO, R. A. Delphi: uma ferramenta de apoio ao planejamento prospectivo. Cadernos de Pesquisa em Administração, São Paulo, v. 1, n. 12, p. 54-65, 2000.

WUNDER, Sven. Payments for environmental services: Add nuts and bolts. Cifor - Occasional Paper, Indonesia, N. 45, p.1-32, 2005. 